\title{
Retrato musical de Julian Bream por Leo Brouwer
}

\author{
Teresinha Prada
}

Universidade Federal de Mato Grosso | Brasil

$\mathrm{N}$ o dia 14 de agosto de 2020, sentidos lamentos anunciavam em diversos espaços o falecimento de Julian Bream (1933-2020), tranquilamente em sua residência - assim se expressava a maioria dos comunicados reproduzidos nas redes sociais, junto com as mídias digitais e impressas. Associo-me às homenagens póstumas neste texto - é tempo de reverenciar sua memória, no entanto o farei guiada pelo gesto do compositor cubano Leo Brouwer (1939-) que, por meio dos endereços de Facebook e YouTube da editora Espiral Eterna Ediciones, foi uma das muitas vozes que se manifestaram sobre a passagem de Bream. Em um vídeo editado com fotos dos dois consagrados artistas, Brouwer lê uma carta aberta, em um tocante relato, com mostras de afeto e gratidão a Bream ${ }^{1}$.

FIGURA 1 - Carta aberta de Brouwer: "Sobre Julian Bream”.

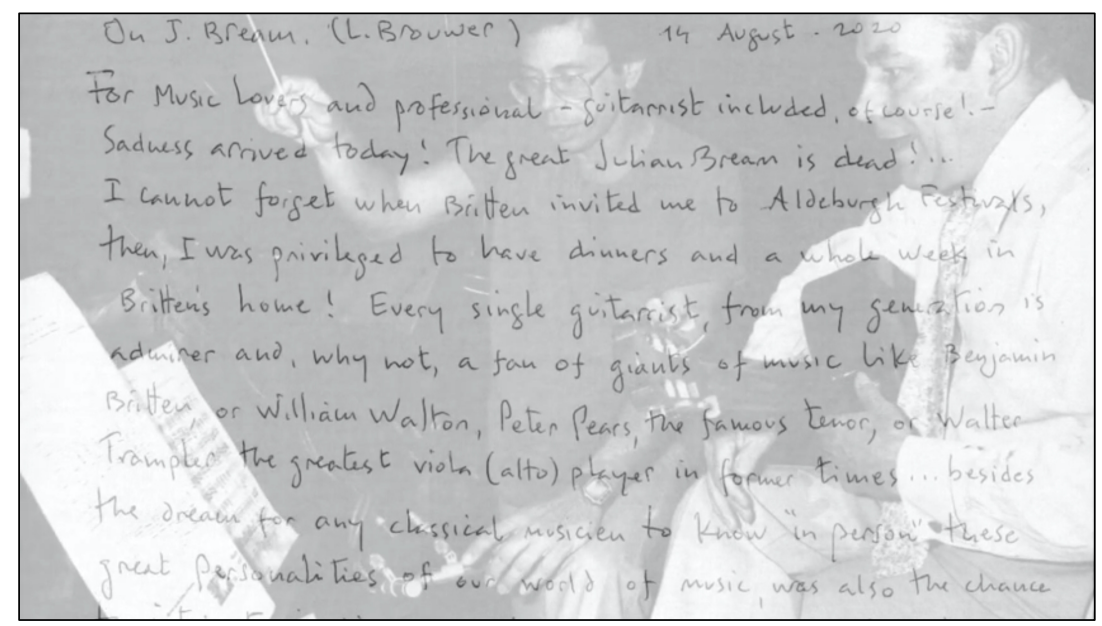

Fonte: Imagem capturada do vídeo no Canal de YouTube da Espiral Eterna Ediciones.

\footnotetext{
${ }^{1}$ Veja aqui o relato https://youtu.be/rHaDT0wrLTQ
} 
Julian Bream foi um mestre incontestável, artista de enorme produção e vivacidade, com grande interesse na diversidade cultural - esteve em uma espécie de intercâmbio musical na Índia, amava o jazz-cigano de Django Reinhardt e sua relação com a Espanha era intensa. Bream também esteve no Brasil, que soube retribuir à altura sua difusão de Heitor Villa-Lobos (em discos, vídeos e concertos, quase a integral da obra villalobiana - faltou somente o Chorinho), quando o agraciou com a Medalha Villa-Lobos, recebida das mãos da presidenta do Museu, a viúva do compositor, Mindinha, em 1979, ocasião em que se apresentou em concorrido concerto na Sala Cecília Meirelles.

FIGURA 2 -Contracapa do LP dedicado a Villa-Lobos, Bream mostra a Medalha, ao lado de Mindinha.

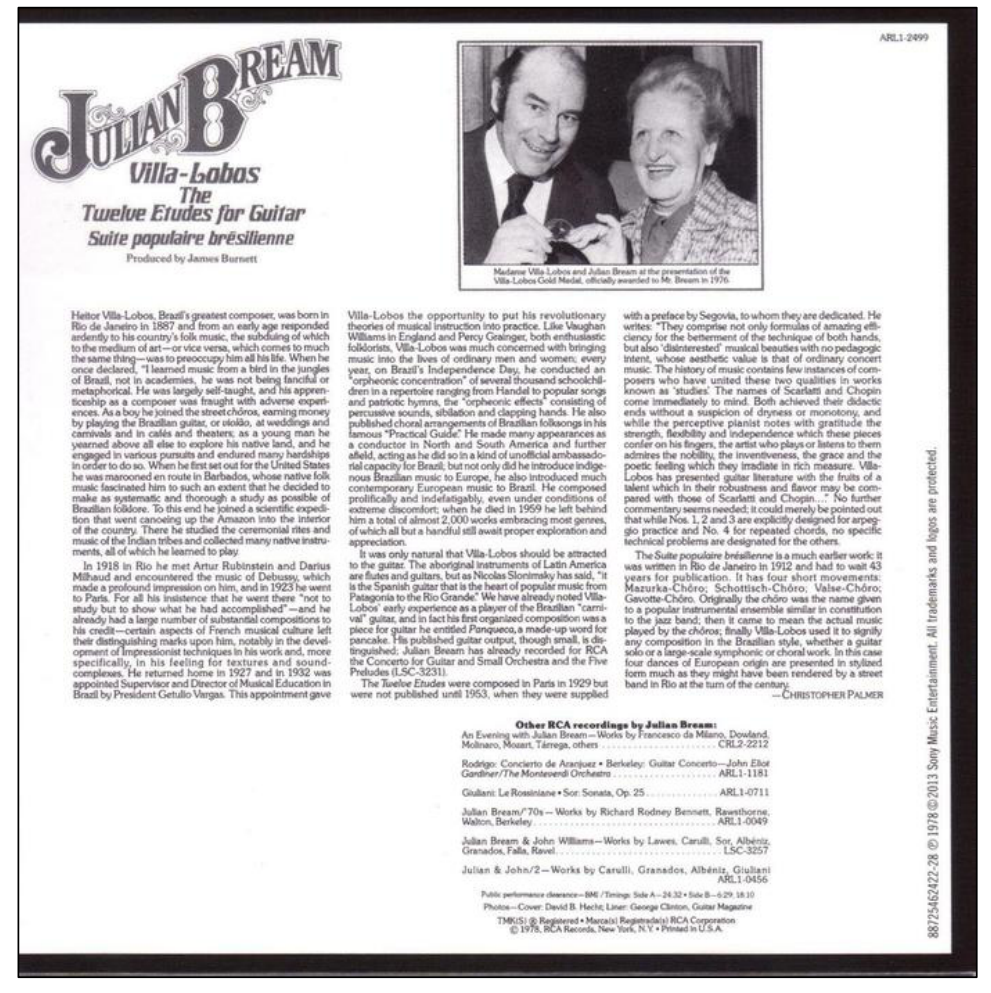

Fonte: Página oficial de Julian Bream²

$\mathrm{Na}$ carta aberta de 14 de agosto de 2020, Brouwer faz um tributo a Bream pela sua maestria como músico e seu trabalho incansável de alargamento do repertório violonístico aos compositores contemporâneos. Ao relatar como o conheceu em 1971, convidado ao Aldeburgh Festival por

\footnotetext{
${ }^{2}$ Disponível em http://www.julianbreamguitar.com/villa-lobos--12-etudes-for-guitar-and-suite-populaire-br-
} $\underline{\text { silienne.html }}$ 
Benjamin Britten, Brouwer destaca o legado musical, o mérito em levantar o repertório das cordas dedilhadas da Renascença, que tanto fascinara Brouwer na juventude, apresentado a esta vertente por seu professor, Isaac Nicola - por isso tanta emoção é descrita pela oportunidade de estar junto a Bream em Aldeburgh; o cubano equipara Bream a Segovia, em pontos como a maestria e ampliação de obras musicais para o violão, e finaliza com um íntimo e comovedor adeus.

Esse conciso relato, de pouco mais de três minutos, fez-me lembrar de outras ocasióes em que Brouwer já mencionara sua experiência e amizade com o inglês, por meio da composição do primoroso Concerto Elegíaco, período em que conviveram de perto, em uma relação que perduraria. O interessante é interpretar a fala de Brouwer sobre este concerto: "um retrato de Julian Bream (...) triste, enérgico, nostálgico, inteligente, neurótico”3.

A história que Brouwer relata sobre a encomenda diz muito sobre a personalidade e a música de Bream. Segundo Brouwer, "Bream não tocava música latino-americana (...) só Villa-Lobos”, ele não apreciava tocar o repertório latino-americano, no entanto, ao ouvir o concerto para violino e orquestra (1976) de Brouwer no rádio, teve a iniciativa de encomendar o concerto - o qual se chamará Elegíaco. Em depoimentos, Brouwer expressa-o veementemente como um "concerto biográfico” e representativo da psique de Bream ${ }^{4}$.

Se levarmos adiante essa expressão e o retrato reproduzido por Brouwer de um Bream "sad, aggressive, nostalgic, intelligent, neurotic”, a cronologia deste concerto precisa começar um pouco antes da première do Elegíaco: Julian Bream teve um acidente de carro, em julho de 1984; em depoimento a Chris Kilvington (1993) na Classical Guitar Magazine, Bream afirma como o medo que teve de não poder tocar mais o fez se entregar, com extrema disciplina, a uma prática diária gradual de recuperação técnica da mão direita, e, felizmente, bem-sucedida nos meses seguintes, inclusive cumprindo uma turnê estadunidense no mesmo ano.

\footnotetext{
${ }^{3}$ No original: “a portrait of Julian Bream” (...) sad, aggressive, nostalgic, intelligent, neurotic”. Fonte: programa de rádio intitulado Classical Guitar Alive! de Tony Morris, originalmente de 2000, disponível em: https://beta.prx.org/stories/337451

${ }^{4}$ Ouça aqui relato extraído do programa Classical Guitar Alive! de 2000, apresentado por Tony Morris: https://soundcloud.com/classicalguitaralive/leo-brouwer-interview-with-tony-morris-on-julian-bream-conciertoelegiaco-sonata-cga-int-20001, e o programa completo aqui: https://beta.prx.org/stories/337451http://www.guitaralive.org/home.html Também, em 2017, em documentário na Argentina: https://youtu.be/3sj8sTRQikc e uma entrevista de 2014: https://texthafen.ch/files/medien/documents/textarchiv/2014-Leo-Brouwer-Interview-def.pdf
} 
Pouco tempo depois, em 1985, a obra é comissionada pela BBC a Brouwer para que Bream a estreasse, e em 30 de Julho de 1986 o Concerto Elegíaco - terceiro concerto de Brouwer para violão e orquestra - é estreado com a Langham Chamber Orchestra conduzida por Brouwer em Londres. Em 1987, gravam com a RCA Victor Chamber Orchestra, e temos a edição da partitura pela Max Eschig em 1989.

Esse foi o momento de realização do Concerto Elegíaco, de muita comoção, certamente, pela luta e recuperação de Bream.

FIGURA 3 -Capa do LP com o Concerto Elegiaco.

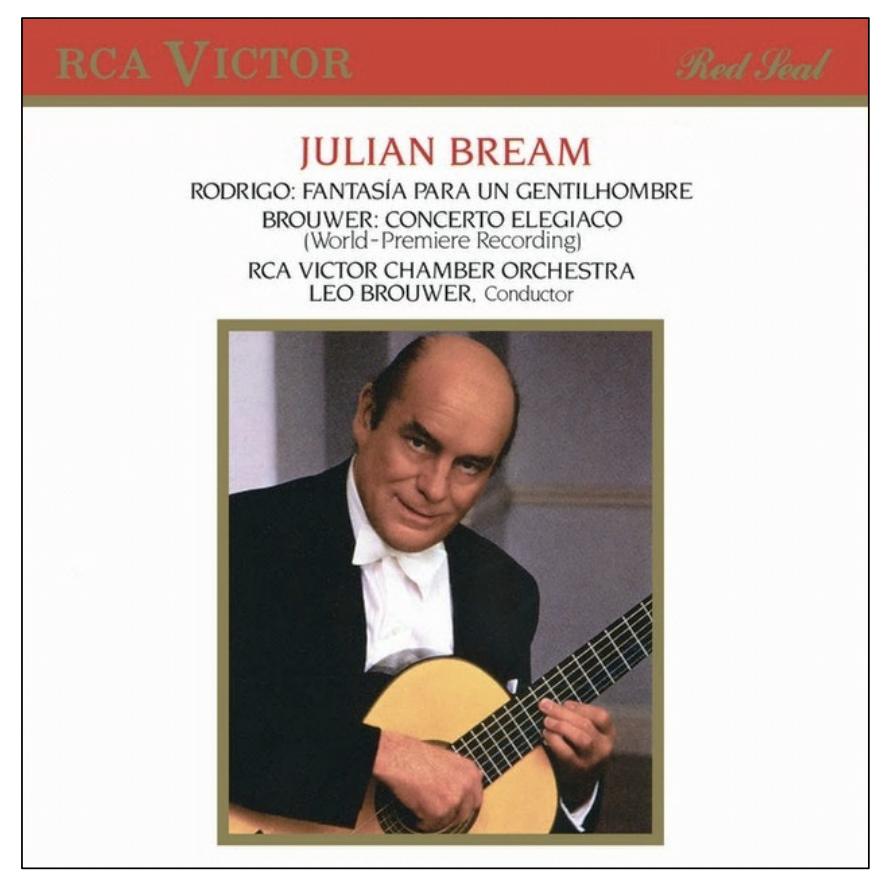

Fonte: Página Oficial de Julian Bream.

A trajetória desse concerto se estende a 1990 com outra obra-prima, a Sonata de Brouwer, dedicada a Bream, na qual nitidamente se percebem gestos do Elegíaco ainda ressoando nessa belíssima produção - afinal é o retrato que fica. Em 1993, Brouwer arranja três movimentos da Iberia de Isaac Albeniz (1860-1909) para Bream em performance no Proms5. Quando se pensava que acabaria aí, temos em 2012 a Sonata V - Ars Combinatoria, comissionada pela Julian Bream Trust.

\footnotetext{
${ }^{5}$ Página da BBC sobre o Festival Proms, disponível em: https://www.bbc.co.uk/events/e58fxij .
} 
Como o Elegíaco está estruturado é algo bem típico do momento em que o compositor cubano vivia em sua trajetória musical - de Minimalismo e retorno à tonalidade -, afastando-se do experimentalismo radical das décadas de 1960 e 1970. O uso de um mínimo material temático (o motivo do concerto, que inicia com um solo de violão) e uma linguagem tonal estendida reiteram o que Brouwer costuma apontar como hiper-Romanticismo (a propalada terceira fase de Brouwer). Neste contexto, vem bem acertada a ideia de partes e o todo composicional por meio de uma montagem/combinação de anotações/esboços (como Jonathan Leathwood aponta em uma palestra $^{6}$ ) e o olhar para o todo da obra - procedimento fundamental, como sustenta Brouwer (em entrevista a Constance McKenna, [1988]) formando a estrutura desse concerto; além do violão, não se pode deixar de falar do papel da percussão no Elegíaco quase como um contínuo do instrumento solista.

O Elegíaco como um Portrait of Bream parece já ter sido visto, por ocasião de sua estreia, na leitura feita por Colin Cooper (1926-2012) em seu artigo When Bream met Brouwer, e que residiria nas ideias de dramaticidade, tragédia e elegia com um pouco de romance, como sustentara Cooper (1987). O melancólico motivo inicial é subitamente alternado pelas entradas da orquestra. Tudo não passaria de uma construção cultural, e o que predomina aqui é a leitura de Cooper que se enlaça com a afirmação de Brouwer.

Minha leitura desse possível retrato de Bream reside no inusitado segundo movimento Interlude, praticamente um solo do violão, quase uma cadenza antecipada, cuja profusão de ornamentos me possibilita fazer a associação desse concerto, de um tonalismo estendido, ao passado modal do violão e à família das cordas dedilhadas, a fase extremamente difundida de Bream com o alaúde e depois a vihuela - de tantas que são as apojaturas em belos trinados e grupetos dessa seção e da obra. A reexposição de parte do primeiro movimento no terceiro (Finale-Toccata) fortalece algumas ideias musicais mais que outras, e do que é reiterado pelo compositor me sugere uma estética de eufóricas old folksongs, de origens escocesas - seria outra nuança do retrato de Bream?

Inglaterra e Cuba - duas ilhas - ambos Bream e Brouwer, homens nascidos ao lado do mar, abertos e inconformados, se perguntavam, na mesma década de 1950, onde estariam os grandes

\footnotetext{
${ }^{6}$ 4.o Festival Leo Brouwer: curso de pós-graduação Escola de Comunicação e Artes/Universidade de São Paulo: Conversas com Julian Bream - Prof. Jonathan Leathwood. Disponível em: https://youtu.be/9u_jTLdijig
} 
autores modernos para violão? Bream foi atrás desses compositores, Brouwer foi ser um destes raros compositores.

Diferentemente de Segovia, interessado em ampliar o repertório do violão de viés na tradição tonal, o interesse de Bream era a estética inovadora, no mínimo moderna, como a neoclássica. Iniciou assim uma parceria compositor e intérprete, na qual era necessário ensaiar, influir com eles, principalmente porque os compositores britânicos não eram violonistas; em um momento póssegunda-guerra, os contemporâneos de Bream eram notáveis criadores sem experiência com a escrita nem contato com instrumento; no final da década de 1950 as peças começam a fluir, uma após outra, das quais se destaca a música de Benjamin Britten (1910-1976). Interessante: o que Manuel de Falla fez ao violão com Homenaje a Debussy em 1920, Britten faz com a Nocturnal (1963) - as duas décadas do século XX símbolos da vanguarda. Brouwer será o único latino-americano e compositor-violonista nessa empreitada.

Se a Nocturnal é o ponto culminante da intensa atividade de Bream em contribuição ao repertório ampliado com modernidade, o Concerto Elegíaco é o amalgama sonoro da sua existência, desafiadoramente retratado por Brouwer que assim o afirmou. Tudo é uma questão de interpretação, como Bream (2003) mesmo afirmara a respeito de suas várias incursões no repertório espanhol - ele via a cultura espanhola com um olhar de alteridade, e via o que se destacava nessa cultura, o que, por vezes, um espanhol não destacaria, pois lhe é inseparável; Brouwer viu no londrino Bream o que lhe era mais notável, sua maestria a toda prova, seu enlace com o passado do violão, sua vitalidade, lutas e dramas e muita persistência - as idiossincrasias de Bream.

Fiz meu Doutorado em História, numa linha chamada História da Cultura, lembro-me de um professor que dizia que 50 anos não é nada em termos de distanciamento temporal para se considerar os marcos históricos, isso explica o aparente desaparecimento de algumas personalidades da história e o seu repentino "resgate", que nada mais é que o Tempo fazendo o seu trabalho, reajustando a pessoa ao seu devido lugar na avaliação da história. Então, se a Bream já lhe era e é atribuído o referencial de tantas contribuiçôes, seu espaço será cada vez mais consolidado, e que venham muitas pesquisas e elegias a este memorável artista. 


\section{REFERÊNCIAS}

BREAM, Julian. My Life in Music (DVD). Music on earth, 2003.

COOPER, Colin. When Bream met Brouwer for the Concerto Elegíaco, Classical Guitar Magazine, 1987. Disponível em: https://classicalguitarmagazine.com/when-bream-met-brouwerfor-the-concerto-elegiaco/

KILVINGTON, Chris. Julian Bream on Recovering From Injury, Jazz Guitarists, \& the Dearth of Modern Guitar Composers. Classical Guitar Magazine, 1993. Disponível em: https://classicalguitarmagazine.com/julian-bream-on-recovering-from-injury-jazz-guitarists-thedearth-of-modern-guitar-composers/

MCKENNA Constance, An Interview With Leo Brouwer, Guitar Review, N. 75, Fall, 1988.

\section{SOBRE A AUTORA}

Teresinha Prada - Bacharel em Violão pela Universidade Estadual Júlio de Mesquita Filho (UNESP); Mestre em Comunicação e Cultura pelo Programa de Integração da América Latina da Universidade de São Paulo (PROLAM/USP); Doutora em História Social pela Faculdade de Filosofia, Letras e Ciências Humanas (FFLCH/USP); Professora Associada da Faculdade de Comunicação e Artes da Universidade Federal de Mato Grosso (FCA/UFMT), docente do Bacharelado em Violão e do Programa de Pós-graduação em Estudos de Cultura Contemporânea (ECCO/UFMT); líder do Núcleo de Estudos de Composição e Interpretação da Música Contemporânea (UFMT); integrante do Núcleo Caravelas CESEM/Universidade Nova de Lisboa; autora dos livros Violão: de Villa-Lobos a Leo Bronwer (2008) e Gilberto Mendes: vanguarda e utopia nos mares do sul (2010). ORCID: https://orcid.org/0000-0001-7817-2417. E-mail: teresinha.prada@gmail.com 